\title{
Income Distribution in Europe and the United States
}

A B Atkinson, Nuffield College, Oxford

\section{Introduction}

This paper assembles, and presents in a straightforward way, empirical evidence about the personal distribution of income in Europe and makes a comparison with the United States. It seeks to answer the following questions. Is income inequality in the countries of Europe much less than in the United States (US)? Does this imply that low income families in the US are actually worse off than their counterparts in Europe, despite the higher average income in the US? Is this a new situation in that inequality has been increasing faster in the US than in Europe? Or have there been similar trends on both sides of the Atlantic? How far would the situation change if we were to consider the European Union (EU) as a whole? Would the degree of inequality in the European Union, encompassing countries as different as Germany and Portugal, be comparable in magnitude to that in American Union, encompassing states as different as Connecticut and Mississippi?

The comparison of income distributions across countries, or across time, raises many problems. We need to decide what we want to measure and how far we can measure it on a comparable basis. A brief account of these issues is given below; they are discussed in more detail in Atkinson, Rainwater and Smeeding (1995).

Inequality of What Among Whom?

Invited lecture at the Annual Conference of the European Association of Labour Economists, Lyon, September 1995. The paper is based on research under the European Community Human Capital and Mobility Programme and draws on a project carried out as part of the Luxembourg Income Study in conjunction with Lee Rainwater and Tim Smeeding (Atkinson, Rainwater and Smeeding, 1995). 
In this paper, attention is concentrated on the distribution of disposable money income, that is income after direct taxes and including transfer payments. Several points should be noted:

a) income rather than consumption is taken as the indicator of resources;

b) the definition of income falls considerably short of a Haig-Simons comprehensive definition, typically excluding much of capital gains, imputed rents, home production, and income in kind;

c) no account is taken of indirect taxes nor of benefits from public spending such as health care or education or subsidies, although cash transfers, and "near-cash" transfers such as food stamps and housing benefit, are included;

d) the period of assessment is in general annual (although the United Kingdom (UK) evidence relates to weekly or monthly income).

These points mean that the variable measured may depart from that regarded as ideal. They also mean that the results may not be comparable across countries: for example, one country may help low income families through housing benefits (included in cash income), whereas another provides subsidised housing (not taken into account).

To the question "among whom", the answer here is the simplest: the distribution is that among individuals. The unit of assessment is however taken as the household, in that the incomes of all household members are aggregated and then divided by an equivalence scale to arrive at individual equivalent income. The equivalence scale is taken, for simplicity, to be the square root of the household size, so that the income of a household of 4 persons is divided by 2.0. The choice of the household, rather than a narrower unit such as the spending unit or the family, is open to debate. It assumes a degree of income-sharing within the household which may not take place. Moreover, the choice of unit may affect comparisons across countries on account of differing household structures and/or differences in the form in which data are collected. The same applies to the choice of equivalence scale, and alternatives are considered. 


\section{Data Sources}

Table 1 lists the countries covered and the origin of the data used. The great majority are drawn from household income surveys, or their equivalent, and take advantage of the availability of micro-data in the Luxembourg Income Study (LIS). LIS assembles in one place a database containing survey data from many countries and places them as far as possible on a consistent basis. Access to the micro-data means that it is possible to produce results on the same basis starting from individual household records: for example, it is in principle possible to make any desired adjustment for household size. (The estimates for Portugal and Spain were calculated separately and may be less fully comparable. The results for these countries are therefore shown in brackets.)

The aim is to increase the degree of cross-national comparability, but complete crossnational comparability is not attainable. Comparability is a matter of degree, and all that one can hope for is to reach an acceptable level. Moreover, one has to recognise that the resulting estimates are not likely to be the most accurate estimates which can be produced for any one country. A critic may say that the procedure reduces all data sets to the lowest common denominator. The results which follow should be read with these qualifications in mind.

\section{Incomes in Europe and the US in the late 1980s}

This section looks at the shape of the distribution of disposable income in fourteen European countries and the United States. The European countries cover all EU members, apart from Austria, Denmark and Greece, plus Norway and Switzerland. In the majority of cases, the 
results refer to the period 1985-1990, but some relate to the start of the 1980s (Spain and Switzerland). I begin by considering disposable income per equivalent adult, (using the equivalence scale of household size to the power of a half), and by looking at percentiles of the median.

\section{Percentiles of the Distribution}

The first method of presentation (Figures 1 and 2) expresses the percentiles of the distribution as percentages of the median. It is immediately apparent from Figure 1 that the position of the bottom decile in the United States is quite different: it is about a third of the median in the US, compared with figures in excess of $45 \%$ in Europe. The lowest income group fares much worse in the US. (It should be noted that the figures already include income-tested transfers such as food stamps.) Among the European countries, the lower ratios tend to be found in Southern Europe. The bottom decile appears to be related to latitude, if Ireland is included with Southern Europe. This emerges even more clearly when we look at the top decile (Figure 2), with Scandinavia having the smallest values: the top $10 \%$ have incomes only about $50 \%$ more than the median, compared with $100 \%$ more than the median in the Iberian peninsular. But we also see that at the top decile the big difference between the US and Southern Europe disappears.

Before looking more closely at these figures, we should consider their sensitivity to the method of calculation. This could be examined in many different ways; here I test only the sensitivity to the method used to calculate equivalent income. Figure 3 shows the impact of three different equivalence scales on the ratio of the top decile to the bottom decile, referred to as the decile ratio. The middle one is that used already (square root of household size, denoted SQ RT); the left hand one indicates what happens if no adjustment is made for household size (NO ADJ); 
and the right hand one is based on per capita income (PER CAP). These three calculations can be seen as varying the equivalence scale according to the formula, $\mathrm{N}^{\mathrm{s}}$, where $\mathrm{N}$ is the number of household members and $s$ is a parameter varying between 0 (no adjustment) and 1 (per capita). On this scale, the two outer calculations represent limits, but they are not necessarily limits on the differences which could arise with many-parameter equivalence scales, such as those which vary with age.

We can see from Figure 3 that there is a big difference between US and European countries for all three measures. This conclusion is not sensitive to the method. At the same time, the position of individual countries can be materially affected, as is shown in Figure 3 by the cases of the UK, France and Sweden. With no adjustment, there is no difference between France and Sweden, and the UK has a higher decile ratio. With a per capita calculation, on the other hand, there is little difference between the UK and France, and Sweden has a lower ratio.

\section{Lorenz Curves}

A more common form of presentation of income distribution statistics is in terms of shares of total income, which are the ingredients for the conventional Lorenz curve. Table 2 shows the cumulative shares by decile groups, where $S_{10}$ denotes the share of the bottom 10 percent, $S_{20}$ denotes the share of the bottom 20 percent, etc. The countries are listed in order of the share of the bottom decile group, $S_{10}$, which in Europe ranges from some $2 \frac{1}{2}$ percent in the UK to $4 \frac{1}{2}$ percent in Finland.

The share of the bottom decile group gives the initial ranking of the Lorenz curves, but the Lorenz curves may subsequently cross. The decile shares are used to test whether or not the Lorenz curves cross. Treating any difference as significant, there are in fact a high proportion of 
situations where a Lorenz comparison can be made. Of the 91 possible pair-wise comparisons of the 14 European countries, there are 68 cases where one Lorenz curve dominates the other. If, to make approximate allowance for the errors surrounding the estimates, cases are excluded where the differences for all decile shares are less than 1 percentage point, then there are 66 cases of Lorenz dominance. In more than 70 percent of cases we have an unambiguous ranking. (It would clearly be possible to calculate the sampling errors associated with the Lorenz curve, and require that one curve be significantly different from another at a specified level of confidence. However, this focuses on sampling error to the exclusion of other, non-sampling, error, which may be quantitatively more important.)

The partial ordering resulting from the Lorenz comparisons (taking only those cases where the difference is 1 percentage point or larger) are summarised in Figure 4 in terms of a Hasse diagram. The countries towards the top of the diagram have the lower levels of inequality, and where a line can be traced downwards from country A to country B this implies that the Lorenz curve for country A is superior to that of country B. Finland dominates all countries, followed by Benelux, Norway, Sweden and Germany. There appears to be a clear grouping of mainland Northern Europe at the top. In the middle are France, Italy, the UK and Portugal, which cannot be ranked one against the other. The Lorenz curves for Italy and Portugal are close; those for France, and even more the UK, start off lower and end up higher. It may be noted that, while the Lorenz curve for the US starts off lower than all, it crosses 5 of the European Lorenz curves, and ends up with the same share for the bottom 90 percent as France.

\section{$\underline{\text { Gini Coefficients }}$}


Where the Lorenz curves cross, the use of a summary measure of inequality yields a complete ranking, although different measures may generate different such rankings. In Figure 4 are shown the Gini coefficients (not including Portugal or Spain). That for the US is $34.1 \%$, the highest value of all. This may be compared with the average for the $12 \mathrm{EU}$ countries, weighted by population, which is $28.8 \%$. (This figure includes Portugal with a Gini coefficient of 31 percent and Spain with a coefficient of 32 percent; Austria, Denmark and Greece are excluded.)

Reference was made earlier to the geographical pattern of inequality. This should not be taken too seriously, but it does draw attention to the fact that there may be reasons to expect the degree of inequality to vary systematically across countries. In the days when people believed in the Kuznets (1955) curve, with inequality first rising and then falling with the level of development, then the US might be expected to be in the vanguard and hence to have a lower Gini coefficient. The trends over time are taken up in Section 3. Other writers, such as Pryor (1973) and Wiles (1974), have argued that inequality may be greater in countries which are larger. This is taken up in Section 4.

\section{$\underline{\text { Conclusion }}$}

The overall degree of income inequality in the US, as measured by the Gini coefficient, is higher than that found in any of the European countries studied here. At the same time, the difference from the European average - some 5 percentage points - is less than the range found within the European Union. The difference between Finland and Sweden, on one hand, and Switzerland and Ireland, on the other, is about twice this amount. The most striking difference between the US and Europe is at the bottom of the distribution. 


\section{Inequality and Differences in Average Income}

Freeman (1994) has recently shown how differences between the United States and Europe in the distribution of earnings mean that the low paid in the United States fall far behind many of their European counterparts. According to his estimates, the hourly compensation in purchasing power of the American man at the bottom decile is half that of the comparable Italian (1994, p 13). How far is the same true of household disposable incomes? A priori, one may expect that the differences in transfer systems would intensify the difference. After all, the United States has no child benefit scheme and only limited unemployment benefits. The direct tax system may well be less progressive. On the other hand, the concentration of wealth in the United States has historically been less than in the UK.

The comparison of real income levels across countries is a subject which has long been debated in the literature. There are a number of objections which can be made to the procedure adopted here, which is to convert mean income levels to the average in the European Community (EC) in 1990 based on National Disposable Income per head calculated using purchasing power parities (OECD, 1992, Table C, and population figures from Table D). (National Disposable Income is National Income minus net transfers overseas.) There are many differences between National Disposable Income per head and mean household equivalent income. Countries differ in the significance of retained corporate earnings, in the role of intervening institutions such as pension funds, and in the burden of direct taxation. The purchasing power conversion applied to national income may not be appropriate to household income. The choice of base year may affect the calculation. These reservations need to be borne in mind in considering the estimates presented here. 
The National Disposable Income per head adjusted using purchasing power parities was 39 percent higher in the US in 1990 than in the European Community (the then twelve members). From Table 2 we can see that the share of the bottom $20 \%$ in the US was 5.7 percent. This means that, even allowing for a difference in real mean income of 39 percent, the bottom $20 \%$ in the US would be worse off than an "average European" living in a country where the share of the bottom $20 \%$ was greater than $8 \%$. If we take the concrete case of Germany, where the share of the bottom $20 \%$ is $9.8 \%$, and real income only $18 \%$ lower than in the US, then this group as a whole is $40 \%$ better off than their counterparts in the US. The difference is so large that it is unlikely to be affected by the choice of a different basis for conversion.

The full distribution for four countries (US, Sweden, France and Ireland) is shown in Figure 5 in terms of the income level corresponding to different percentiles. The diagram is like Pen's parade of incomes, except that it starts at the bottom decile and stops at the top decile, thus omitting the dramatics of the extremes. Each income is expressed relative to the EC average at the time. The parade starts with the bottom decile. At this point incomes in the US are lower than those in Sweden and France, although above those in Ireland. The height in the US rises more steeply, but does not cross that for France until around the twentieth percentile and that for Sweden around the thirtieth. This implies that about a fifth of the French population, and more than a quarter of the Swedish population, are better off than their counterparts in the US.

The conclusions regarding absolute levels of income may be stated in terms of the Generalised Lorenz curve (the Lorenz curve adjusted for differences in mean income). The higher mean income in the US implies that it cannot be dominated in a generalised Lorenz sense (since the generalised Lorenz curve terminates at mean income), but conversely the US only dominates a relatively small number of countries. If we construct the generalised Lorenz curve 
from the shares of decile groups in Table 2, then the US dominates Spain, Portugal, Ireland and the UK. Put another way, a Rawlsian concerned only with the average income of the lowest decile would rank the US after 10 of the 14 European countries.

\section{$\underline{\text { Conclusion }}$}

The broad conclusion suggested by these estimates is that differences in the distribution of income can be sufficient to outweigh differences in average incomes. The precise magnitudes may be changed by alternative methods of conversion, but it remains likely that in the late 1980s the poorest families in the US fared less well than those in a number of European countries.

\section{Diverging Trends in Income Distribution?}

The greater inequality of incomes in the United States than in Europe may now be regarded as well-known. However, this has not always been so. In the 1950s, Lydall and Lansing in their comparative study of the US and Great Britain noted the "relative similarity of the Lorenz curves of income" (1959, p 60). (Although, interestingly, they did find more low income families in the US.) When Sawyer carried out his study for the OECD he did not find that the US was an outlier in the early 1970s: for example, he shows the Gini coefficient as being less than that in France, Italy and West Germany (1976, Tables 4 and 6). Is the current position of the US, then, the result of divergent trends over the past quarter century?

In order to examine this question, I have assembled the results of a selection of national studies of income inequality (and now extend the coverage to include Denmark (DK)). It should be stressed that these national studies are not designed for purposes of international comparison, 
and they are not all based on the same types of sources, the same concepts of income, or the same methods of calculation. For several countries, I have linked a number of series, from different sources, and there is no reason to suppose that the differences between the series have necessarily remained unchanged over time.

From Figure 6, it is clear that income inequality has increased in the US. As it was put in the 1994 Economic Report of the President, "starting some time in the late 1970s, income inequalities widened alarmingly in America" (1994, p 25). From the mid-1970s to 1992 the Gini coefficient rose by some 4 percentage points. What was perhaps more "alarming" than the size of the increase was the fact that the expectation had been that inequality would fall over time. It is worth remembering that twenty years ago Jan Tinbergen wrote that

"The trend in income shares of the lowest groups over the last decades has been upward, that of the highest groups downward.

If the linear trend in inequality indicators were to continue, halving inequality would take some 25 years or one generation" (1975, p 27).

From Figure 6, we can see that this expectation continued to have some basis in the 1970s. While it would be wrong to describe it as an inexorable trend, there were significant periods when inequality fell: in the first half of the 1970s in the UK, for the period shown up to 1981 in Sweden, and up to the mid-1980s in Denmark. Over the 1970s the US and Europe were diverging. This emerges even more clearly in Figure 7. In all the European countries apart from West Germany, there was a fall in inequality, taking the period between 1970 and the mid-1980s as a whole. In Finland, France and Italy the fall was some 5 percentage points or more.

The picture in the 1980s is, of course, rather different. If we take the period from 1985 to 1989 or later, for which Figures 6 and 7 show information for 9 countries, then the findings are mixed. In the UK there was a marked rise in income inequality: from 1986 to 1991 the Gini 
coefficient in the UK increased by 5 percentage points. There was a sharp upward movement in Sweden between 1988 and 1991. For the other countries in Figure 6 the increase in the late 1980s is less marked, as is illustrated by comparing the UK and Netherlands. If we turn to Figure 7, then is no obvious upward trend in Italy or Finland, and only a rise of 1 percentage point in France and West Germany.

\section{Conclusion}

In the 1970s a gap widened between the US and Europe as there continued to be periods when inequality fell in most of the latter countries, whereas inequality rose in the US. By the second half of the 1980s, inequality had ceased to fall in most European countries. In some, but not all, inequality began rising, most markedly in the UK.

\section{Distribution of Income in Europe as a Whole}

In his analysis of income distribution in the USSR, Wiles argued that it "is a very big country, so surely it is bound to show more inequality on that ground alone" (1974, p 53), attributing this to the existence of "regions with deep historical differences". Is the difference in inequality between the US and the countries of Europe due to the scale of the former? Put another way, if we consider the European Union as a whole, do we find a comparable degree of inequality to that in the US?

The construction of a Europe-wide distribution is a project of some interest. It is also one that poses a number of problems, and the estimates for the European Union presented here are at best a proto-type. They are provisional in two senses. First, I simply apply the purchasing power 
parity conversion procedure used in Section 2 (based on National Disposable Income per head in 1990), and this is open to several objections. Secondly, I have not gone back to the micro-data. Instead, as an indication of the kind of results which may be obtained, I have tried the experiment of estimating the overall distribution from national "meso-tables", which divide the population into 40 groups of equal size (20 groups in the case of Finland, Netherlands, Portugal and Spain), ranked according to their equivalent disposable income (defined in the same way as in earlier sections), where it is assumed that incomes are equal within each group. (This method follows that of Whalley, 1979.) No data are available for Austria, Denmark or Greece, so that the total number of synthetic groups is 400 , covering 325 million out of the European Union population (using 1990 figures) of 348 million. (These figures exclude East Germany.)

The position in which an individual finds herself or himself in the Europe-wide distribution depends on both the average income of their country and its relative degree of inequality. This is illustrated in Figure 8. Sweden has above-average income, and the bottom decile is a relatively larger proportion of the median. Taken together, these factors propel the bottom decile Swede above the bottom quintile of the Europe-wide distribution (see the move to the right in Figure 8). But the top decile Swede, relatively less well-off relative to the median, ends up below the top decile of the Europe-wide distribution. In the middle, the distributional differences are less marked, and from Figure 8 we can see that the lower quartile Swede occupies much the same position as the upper quartile Irish person.

Table 3 shows the decile shares in the "Europe-wide" distribution, compared with those in West Germany (the least unequal of the larger countries) and Italy (among the more unequal). The share of the bottom decile group is less than that in either country, although still 1 percentage point higher than in the United States. The bottom 50 percent in the Europe-wide distribution has 
a share of 29.5 percent, compared with 28.7 percent in Italy and 26.2 percent in the United States. The provisional estimates presented in this section can be refined in a number of ways, and the method of calculation (assuming equal incomes within groups) tends to understate overall inequality, but for the present they suggest that the "Europe-wide" distribution is less unequal than that in the United States.

\section{Concluding Comments}

The evidence described in this paper requires fuller examination. Only a few broad features of the overall distribution have been described, and it would be interesting to subject the differences between countries to a thorough statistical analysis. The distribution within subgroups of the population is a subject which needs to be investigated, and a decomposition may cast light on the differences between countries in changes over time. How far, for example, have episodes of rising inequality been associated with an increased proportion without income from work? Decomposition analysis may also illuminate the role of inequality between and within the countries of Europe.

For the present, this review suggests the following broad conclusions:

$\diamond \quad$ the US appears to have distinctly higher income inequality than Europe, with the difference largely arising at the bottom of the scale,

$\diamond \quad$ within Western Europe, certain groupings may be made: the Scandinavian countries, Benelux and West Germany have less inequality in disposable equivalent income; Southern Europe and Ireland have higher inequality, with France and, to some degree, the UK and Italy, occupying an intermediate position, 
$\diamond \quad$ differences in the distribution of income can be sufficient to outweigh differences in average incomes: the poorest families in the US fare less well than those in a number of European countries,

$\diamond \quad$ in the 1970s a gap widened between the US and Europe as there continued to be periods of falling income inequality in most of the latter countries; by the second half of the 1980s, however, inequality had ceased to fall in most European countries, and in some, but not all, inequality began rising,

$\diamond \quad$ the largest, most sustained, episode of increasing inequality in the 1980s was in the UK,

$\diamond \quad$ the proto-type estimates suggest that the "Europe-wide" distribution, viewing the European Union as an entity, is less unequal than that in the United States. 
Table 1 Sources of data

\begin{tabular}{|lll|}
\hline Country (abbreviation) & Year & Source \\
\hline Belgium (BE) & 1988 & \\
Finland (FI) & 1987 & Household panel study \\
France (FR) & 1984 & Household income survey \\
Germany (GE) & 1984 & Income tax records \\
Ireland (IR) & 1987 & Socio-economic panel survey \\
Italy (IT) & 1986 & Household income survey \\
Luxembourg (LU) & 1985 & Household income survey \\
Netherlands (NL) & 1987 & Household panel study \\
Norway (NO) & 1986 & Household survey \\
Portugal (PO) & 1990 & Household income and wealth survey \\
Spain (SP) & $1980 / 1$ & Household income and expenditure survey \\
Sweden (SW) & 1987 & Household income and expenditure survey \\
Switzerland (CH) & 1982 & Household income survey \\
UK & 1986 & Household income and wealth survey \\
\hline & 1986 & Household income and expenditure survey \\
US & & \\
\hline
\end{tabular}

Note: (i) Throughout the paper "Germany" refers to the former West Germany.

(ii) The data for Portugal and Spain were supplied separately and may be less directly comparable.

Sources:

Portugal: supplied by C Rodrigues (see Rodrigues, 1993).

Spain: supplied by M Mercader (see Mercader, 1993).

All other: from LIS study, see Atkinson, Rainwater and Smeeding (1995). 
Table 2 Income distribution in European countries 1980s:

\section{cumulative decile shares of total income \%}

\begin{tabular}{|lccccccccc|}
\hline & & & & & & & & & \\
& S10 & S20 & S30 & S40 & S50 & S60 & S70 & S80 & S90 \\
FI & 4.5 & 10.8 & 18.1 & 26.4 & 35.6 & 45.6 & 56.6 & 68.6 & 82.2 \\
LU & 4.3 & 10.2 & 17.1 & 24.8 & 33.5 & 43.1 & 53.9 & 66.0 & 80.4 \\
BE & 4.2 & 10.2 & 17.1 & 25.0 & 33.8 & 43.5 & 54.3 & 66.4 & 80.3 \\
NL & 4.1 & 10.1 & 16.9 & 24.5 & 33.0 & 42.5 & 53.2 & 65.3 & 79.4 \\
GE & 4.0 & 9.8 & 16.6 & 24.2 & 32.9 & 42.5 & 53.2 & 65.3 & 79.4 \\
NO & 3.9 & 9.8 & 16.9 & 24.9 & 33.9 & 43.7 & 54.6 & 66.7 & 80.6 \\
(PO) & 3.4 & 8.0 & 13.9 & 20.9 & 28.9 & 38.1 & 48.5 & 60.8 & 75.8 \\
SW & 3.3 & 9.5 & 16.9 & 25.3 & 34.6 & 44.8 & 55.9 & 68.2 & 81.9 \\
IT & 3.1 & 8.0 & 13.9 & 20.7 & 28.7 & 38.0 & 48.7 & 61.2 & 76.2 \\
FR & 3.0 & 8.3 & 14.6 & 21.8 & 29.9 & 39.1 & 49.5 & 61.6 & 76.3 \\
CH & 2.8 & 8.0 & 14.1 & 21.0 & 29.0 & 37.8 & 47.7 & 58.9 & 72.5 \\
(SP) & 2.8 & 7.4 & 13.2 & 20.1 & 28.2 & 37.5 & 47.9 & 60.2 & 75.5 \\
UK & 2.5 & 7.5 & 13.5 & 20.5 & 28.7 & 38.2 & 49.1 & 61.8 & 77.1 \\
IR & 2.5 & 7.1 & 12.6 & 19.3 & 27.1 & 36.3 & 47.0 & 59.6 & 75.1 \\
& & & & & & & & & \\
US & 1.9 & 5.7 & 11.2 & 18.0 & 26.2 & 35.7 & 46.9 & 60.2 & 76.3 \\
\hline & & & & & & & & & \\
\hline
\end{tabular}

Note: the results are for the distribution among persons of household disposable income adjusted by an equivalence scale equal to (household size) ${ }^{0.5}$.

Sources: $\quad$ see Table 1. 
Table 3 "Europe-wide" distribution: shares of total income

\begin{tabular}{|l|ll|l|l|}
\hline $\begin{array}{l}\text { Share of decile } \\
\text { group }\end{array}$ & West Germany & Italy & United States & "Europe wide" \\
\hline 10 & 4.0 & 3.1 & 1.9 & 2.9 \\
20 & 9.8 & 8.0 & 11.2 & 7.9 \\
30 & 16.6 & 13.9 & 18.0 & 14.1 \\
40 & 24.2 & 20.7 & 26.2 & 21.3 \\
50 & 32.9 & 28.7 & 35.7 & 29.5 \\
60 & 42.5 & 38.0 & 46.9 & 39.0 \\
70 & 53.2 & 48.7 & 60.2 & 49.8 \\
80 & 65.3 & 61.2 & 76.3 & 77.2 \\
\hline 90 & 79.4 & 76.2 & & 62.3 \\
\hline
\end{tabular}




\section{Sources for Figures}

Figures $1-5$, and 8

See Table 1.

Figures 6 and 7

Denmark (DK) Hansen (1993), Table 3.4

Finland (FI) Uusitalo (1989), Table 5.4 and Uusitalo (1994)

France (FR) 1979-1989 from Bourguignon and Martinez (1995); 1970-1979 from Sandoval (1989, Table 3.3) linked at 1979; 1962-1970 from United Nations Statistical Office (1981, p 108) linked at 1970

West Germany (GE) 1973-1983 (budget survey data) from Hauser and Becker (1993, Table 7); 1983-1990 (panel data) from Hauser and Becker (1993, Table 7) linked at 1983; 1964-1973 from Guger (1989, Chart I) linked at 1973

Ireland (IR) Callan and Nolan (1993), Table 4

Italy (IT) Brandolini and Sestito (1994), Table 2a, interpolated for the years 1985, 1988 and 1990

Netherlands (NL) data supplied by Central Bureau of Statistics, see Atkinson, Rainwater and Smeeding (1995)

Norway (NO) Epland (1992), Tabell 4

Sweden (SW) Gustafsson and Palmer (1993), Annex, with 1991 from revised series linked at 1990

UK Goodman and Webb (1994), page A2 (BHC)

US Nelson (1994), Table 2.1, household income series 1967-1990, with 19611967 family income series linked at 1967, 1991-2 from U.S. Department of Commerce (1993), Table B-3, p B-6 


\section{$\underline{\text { References }}$}

Atkinson, A. B., Rainwater, L., and Smeeding, T., 1995, Income Distribution in OECD Countries: the Evidence from the Luxembourg Income Study (LIS), OECD, Paris.

Bourguignon, F. and Martinez, M., 1995, "A decomposition analysis of the evolution of the family income distribution: France 1979-89", DELTA, Paris.

Brandolini, A. and Sestito, P., 1994, "Mutamenti nella distribuzione del reddito in Italia, 19771991", in Rossi, N., editor, Secondo Rapporto CNEL sulla Distribuzione e Redistribuzione del reddito in Italia, GRETA, Venice.

Callan, T. and Nolan, B., 1993, "Income inequality and poverty in Ireland in the 1970s and 1980s", ESRI Working Paper 43, ESRI, Dublin.

Economic Report of the President, 1994, United States Government Printing Office, Washington, DC.

Epland, J., 1992, "Inntektsfordelingen i 80-årene", Økonomiske analser, No. 2: 17-26.

Freeman, R B, 1994, "How labor fares in advanced economies" in Freeman, R B, editor, Working Under Different Rules, Russell Sage Foundation, New York.

Goodman, A. and Webb, S., 1994, For Richer, For Poorer, Institute for Fiscal Studies, Commentary No. 42, London.

Guger, A., 1989, "The distribution of household income in Germany", WIFO Working Paper 35, Austrian Institute of Economic Research, Vienna.

Gustafsson, B. and Palmer, E. E., 1993, "Changes in Swedish inequality: a study of equivalent income 1975-1991", University of Gothenburg.

Hansen, F. K., 1993, "Social exclusion in Denmark", Center for Alternativ Samfundsanalyse, Copenhagen.

Hauser, R. and Becker, I., 1993, "The development of the income distribution in the Federal Republic of Germany during the seventies and eighties", University of Frankfurt.

Kuznets, S., 1955, "Economic growth and income inequality", American Economic Review, Vol. 45: 1-28.

Lydall, H F and Lansing, J B, 1959, "A comparison of the distribution of personal income and wealth in the United States and Great Britain", American Economic Review, vol 49: 43-67.

Mercader, M., 1993, "The low income population in Spain and a comparison with France and the UK", Welfare State Programme Discussion Paper 95, STICERD, London School of Economics. 
Nelson, C. T., 1994, "Levels and changes in the distribution of U.S. income", in J. H. Bergstrand et al, editors, The Changing Distribution of Income in an Open U.S. Economy, Elsevier Science, Amsterdam.

OECD, 1992, Historical Statistics 1960-1990, OECD, Paris.

Pryor, F L, 1973, Property and Industrial Organization in Communist and Capitalist Nations, Indiana University Press, Bloomington.

Rodrigues, C., 1993, "The measurement and decomposition of inequality in Portugal, 1980/811989/90", Microsimulation Unit Discussion Paper MU9302, Department of Applied Economics, Cambridge.

Sandoval, V., 1989, "Income distribution in France", in G Wolleb, ed, Trends and Distribution of Income, European Federation for Economic Research, Luxembourg.

Sawyer, M., 1976, "Income distribution in OECD countries", OECD Economic Outlook, OECD, Paris.

Tinbergen, J., 1975, Income Distribution, North-Holland, Amsterdam.

United Nations Statistical Office, 1981, A Survey of National Sources of Income Distribution Statistics, United Nations, New York.

U.S. Department of Commerce, 1993, Money Income of Households, Families, and Persons in the United States: 1992, Current Population Reports, Series P-60, No. 184, Washington DC.

Uusitalo, H., 1989, Income Distribution in Finland, Central Statistical Office of Finland, Helsinki.

Uusitalo, H., 1994, "Changes in income distribution during a deep recession", unpublished paper.

Whalley, J., 1979, "The worldwide income distribution: some speculative calculations", Review of Income and Wealth, vol 25: 261-276.

Wiles, P J D, 1974, Distribution of Income: East and West, North-Holland, Amsterdam. 